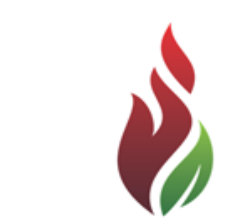

SUSTENERE

Publishing Corporation

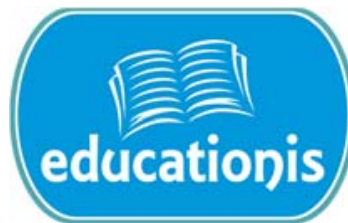

Journals Homepage:

www.sustenere.co/journals

\section{PERCEPÇÃO AMBIENTAL DOS MORADORES DO MARIA DO CARMO, SÃO CRISTÓVÃO, SERGIPE}

\section{RESUMO}

A percepção ambiental positiva é tida como sendo uma tomada de consciência das questões ligadas ao ambiente, o que significa que os indivíduos adquirem conhecimentos que os tornam aptos a agir individual e coletivamente na tentativa de solucionar os problemas ambientais. Nesse sentido, o presente trabalho teve por objetivo avaliar a percepção ambiental da comunidade carente do Conjunto Maria do Carmo em São Cristóvão, Sergipe, procurando verificar se as condições socioeconômicas interferem na relação com o meio em que vivem. Foram entrevistados 100 moradores a partir de questionários contendo 20 perguntas objetivas. Constatou-se que o nível socioeconômico não se constitui em impedimento do ato de perceber o ambiente no qual se está inserido, pois muitos conseguem distinguir o que se deve ou não fazer em relação às problemáticas ambientais, porém uma postura crítica e de ação diante dos problemas expostos ainda não foi alcançada, fato evidenciado pelos problemas ambientais vivenciados.

PALAVRAS-CHAVE: Percepção Ambiental; Educação Ambiental; Aspectos Socioeconômicos.

\section{PERCEPTION OF ENVIRONMENTAL CARMO MARIA OF RESIDENTS, ST KITTS, SERGIPE}

\begin{abstract}
The environmental perception represents a positive awareness of environmental issues, which means that individuals acquire knowlwdge, values, experience and determination that make them able to act individually and collectively to try to solve environmental problems. In this sense, it that this work was proposed with the objective of evaluating the environmental perception of the poor community of the Maria do Carmo, São Cristovão, Sergipe, trying to check whether the socioeconomic conditions affect the relationship with the environmental education in this region. For this purpose we interviewed 100 residents from pre-designed questionnaires containing 20 objective questions. It was found that socio-economic status does not constitute an impediment to the act of perceiving the environment in which he lives, but a critical citizen about these problems has not yet been achieved, as evidenced by environmental problems experienced.
\end{abstract}

KEYWORDS: Environmental Awareness; Environmental Education; And SocioEconomic Aspects.
Educationis, Aquidabã, v.3, n.1, Ago, Set, Out, Nov, Dez 2014, Jan 2015.

\section{ISSN 2318-3047}

\section{SECTION: Articles}

TOPIC: Cultura, Gênero e Subjetividade.

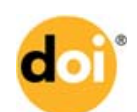

DOI: 10.6008/SPC2318-3047.2015.001.0005

\section{Fabiana Silva Vieira}

Universidade Federal de Sergipe, Brasil http://lattes.cnpq.br/7924741218127218 fabiannavieira@yahoo.com.br

\section{Ana Paula Dantas Messias}

Universidade Federal de Sergipe, Brasil http://lattes.cnpq.br/4445144970934426 matdantas@yahoo.com.br

\section{Douglas de Matos Dias}

Universidade Federal de Sergipe, Brasil http://lattes.cnpq.br/3499657820232206 diasdm.bio@gmail.com

Received: 03/04/2014

Approved: $13 / 01 / 2015$

Reviewed anonymously in the process of blind peer.

\section{Referencing this:}

VIEIRA, S. F.; MESSIAS, D. P. A.; DIAS, M. D.. Percepção ambiental dos moradores do Maria do Carmo, São Cristóvão, Sergipe. Educationis, Aquidabã, v.3, n.1, p.42-49, 2015. DOI:

http://dx.doi.org/10.6008/SPC23183047.2015 .001 .0005 


\section{INTRODUÇÃO}

O crescimento econômico no Brasil aconteceu de modo desenfreado e sem algum planejamento e preocupação com as questões ambientais. As consequências deste processo resultaram em uma intensa urbanização sem mecanismos regulatórios e de controle, trazendo consigo enormes repercussões sobre os riscos da degradação ambiental e suas graves consequências na qualidade de vida da população (BATISTA \& ALBURQUEQUE, 2007). Problemas ambientais como a insuficiência dos serviços básicos de saneamento, coleta e destinação adequada do lixo, condições precárias de moradia, poluição química e física do ar, da água e da terra vêm se agravando cada vez mais e tornam-se mais severos sobre a população carente o que acaba gerando uma crescente degradação das condições de vida, refletindo em uma crise ambiental (PEDRINI et al., 2010).

Para reverter essa situação é necessária uma reincorporação das questões ambientais nas políticas públicas em uma ampla estratégia de desenvolvimento sustentável, enfim, de melhoria da qualidade de vida. A qualidade de vida se expressa mediante a utilização de indicadores sociais concretos e objetivos como a taxa de desemprego, a densidade populacional e outros subjetivos, baseados em informações colhidas diretamente dos indivíduos que compõem uma população em estudo. Não é possível dissociar a qualidade de vida do comportamento individual e coletivo que é resultado de sua organização e do seu desenvolvimento cultural (PELICIONI, 1998; BATISTA \& ALBURQUEQUE, 2007).

O indivíduo como cidadão critico e entendido de seu papel é responsável direto pelo enfrentamento dos problemas socioambientais, para isso, precisa estar cientificamente alfabetizado, politicamente consciente e engajado (GUIMARÃES \& VASCONCELOS, 2006). O saber ambiental se constitui em uma perspectiva para a formação desse cidadão participativo e critico. A educação ambiental deve ser considerada como um processo contínuo, onde os indivíduos e a comunidade tomam consciência do meio ambiente e adquirem conhecimentos, valores, habilidades, experiências e a determinação que os tornam aptos a agir individual e coletivamente na tentativa de solucionar os problemas ambientais (DIAS, 1992).

A educação ambiental deve incorporar as dimensões sociais, políticas, econômicas, culturais, ecológicas e éticas o que significa que a questão ambiental deve ser tratada de um ponto de vista mais amplo, uma vez que, os aspectos anteriormente citados estão intrinsecamente associados, acabando por refletir sobre o meio ambiente. A maioria dos problemas ambientais tem suas origens na miséria, que por sua vez, é resultado de políticas e problemas econômicos concentradores de riqueza e responsáveis pelo desemprego e degradação ambiental (DIAS, 1994). 
Uma das dificuldades para a proteção dos ambientes naturais está na existência de diferenças das percepções dos valores e da importância dos mesmos entre os indivíduos de culturas diferentes ou de grupos socioeconômicos que desempenham funções distintas, no plano social, nesses ambientes. A educação e percepção ambiental despontam como iniciativas eficazes para a defesa do ambiente natural, além de ajudar a reaproximar o homem da natureza, garantindo um futuro com qualidade de vida para todos, uma vez que, acabam por despertarem um maior compromisso e respeito do cidadão com o ambiente a sua volta (SHWARZ et al., 2007; VILLAR et al., 2008; PEDRINI et al., 2010).

Por percepção ambiental pode-se entender como sendo a visão que cada indivíduo tem de perceber o ambiente que o cerca, contexto que o leva, a partir dessa percepção, a interagir 'positiva ou negativamente' com o meio a sua volta, influenciando 'positiva ou negativamente' as pessoas e o ambiente com o qual reage e interage 'direta ou indiretamente', sendo o primeiro passo na direção do processo de conhecimento e do exercício de cidadania ambiental (FERNANDES et al., 2006; VILLAR et al., 2008). Assim, o estudo da percepção ambiental é de fundamental importância para uma melhor compreensão da inter-relação homem-ambiente, levando em conta suas expectativas, satisfações e insatisfações, julgamentos e condutas (VILLAR et al., 2008). Diante do que foi anteriormente exposto é que o presente trabalho foi proposto com o objetivo de se avaliar a percepção ambiental positiva ou negativa da comunidade carente do conjunto Maria do Carmo do bairro Rosa Elze em São Cristóvão, Sergipe, procurando verificar se as condições socioeconômicas interferem na relação com o meio em que vivem.

\section{METODOLOGIA}

O município de São Cristóvão, onde está inserido a comunidade do Bairro Maria do Carmo, tem uma população estimada em cerca de 78.864 habitantes e faz parte da região metropolitana de Aracaju, capital de Sergipe. A comunidade do Maria do Carmo retrata famílias de classe média baixa e que dispõem de precárias condições de saneamento básico.

Para compreender a relação do cidadão são-cristovense com o meio ambiente de sua comunidade foram entrevistados 100 moradores a partir de questionários previamente elaborados contendo 20 perguntas objetivas. Os moradores foram ouvidos no dia 22 de setembro de 2008. Os questionamentos foram feitos visando, inicialmente, estabelecer o perfil socioeconômico, o reconhecimento e a preocupação com os impactos ambientais vivenciados dentre de sua comunidade, além de procurar entender a relação entre o morador e o ambiente. Estabelecidos estes aspectos tentou-se, então, identificar alguma relação entre as condições econômicas e sociais e a percepção ambiental positiva ou negativa, isto é, se o perfil socioeconômico é determinante sobre a tomada de consciência das problemáticas ligadas ao ambiente apresentadas pela população. 


\section{RESULTADOS}

Por meio de observação do grupo de pesquisa foi possível averiguar que o conjunto Maria do Carmo no Rosa Elze, em São Cristóvão, é formado por casas de alvenaria em bom estado de conservação. O esgoto é lançado diretamente nas ruas e é comum a presença de depósitos de lixos a céu aberto, apesar da coleta de lixo ser realizada três vezes por semana, situação comum à maioria dos bairros sergipanos.

A análise dos dados obtidos a partir da aplicação do questionário aos 100 indivíduos residentes no Conjunto Maria do Carmo revelou que 53\% dos entrevistados não concluíram o ensino fundamental ou nunca frequentaram a escola. A maior parte (53\%) não trabalha, sendo donas de casa, aposentados ou estudantes. E uma boa parte (30\%) trabalha no mercado informal no chamado 'bico'. O 'bico' neste trabalho é considerado como sendo uma atividade informal e temporária. As famílias se sustentam (66\%) com uma renda mensal de um ou dois salários mínimos, mas existem aqueles (27\%) que sobrevivem com menos de um salário mínimo, neste ponto é importante ressaltar que em cerca de $60 \%$ das moradias residem mais de quatro moradores aumentando as dificuldades de um sustento digno destas famílias.

Seguindo a caracterização socioeconômica destes moradores, tentou-se avaliar o nível cognitivo sobre as problemáticas ambientais. Cerca de $70 \%$ dos entrevistados identificaram a frequência recorrente de doenças virais como resfriados, gripe e dengue, além de verminoses, micoses e doenças respiratórias. E $90 \%$ dos moradores atribuem a alta incidência de tais doenças à falta de saneamento básico e ao acúmulo de lixos nas ruas do próprio bairro. Os demais não acreditam haver algum tipo de relação. Sobre o incômodo gerado pelo lançamento do esgoto na rua apenas $15 \%$ não se sentem incomodados e a maioria atribui o incômodo a presença do mau cheiro. Quando questionados sobre quem seriam os responsáveis pelos problemas ambientais inclusive aqueles observados no seu bairro $60 \%$ atribuíram a própria comunidade; $16 \%$ aos governantes; e $24 \%$ tiveram a noção de que todos nós integrantes da sociedade, organizados dentro das mais diferentes instituições, profissões ou classes sociais são responsáveis pela manutenção de um meio natural limpo, com qualidade de vida e de um desenvolvimento igualitário e justo.

Procurou-se, também, averiguar o envolvimento dos moradores do Conjunto Maria do Carmo com os problemas ambientais observados no seu bairro, destacando o depósito de lixo nas ruas e no Rio Poxim localizado nas proximidades. Dentre os entrevistados $85 \%$ tem conhecimento sobre coleta seletiva do lixo doméstico, e para $32 \%$ essa é uma situação que faz parte de sua rotina. Cerca de $70 \%$ afirmaram não jogar lixo nas ruas, apesar de ter sido flagrado papel na 
porta de muitas residências. E nenhum afirmou jogar lixo no Rio Poxim, apesar de ser comum a presença de plásticos e recipientes boiando nas suas águas.

\section{DISCUSSÃO}

A comunidade do Conjunto Maria do Carmo, assim como muitas outras espalhadas pelos demais estados brasileiros, são o resultado de um crescimento urbano acelerado e desorganizado, condicionado pelo modelo urbano-industrial característico das sociedades capitalistas em expansão, e estabelecidos de modo polarizado e desigual. A ausência ou baixo alcance das políticas habitacionais, a especulação imobiliária, e a ineficaz ação do Estado contribuíram para o agravamento deste cenário.

As famílias desta região são sustentadas na grande maioria dos casos por valores de até dois salários mínimos, vivendo, assim, com uma renda mensal limitada. A pobreza não se limita somente à insuficiência da renda, mas constitui condições ou síndrome que se reflete em outros tipos de carência como educação e saúde, dentre outros, que acabam por dificultar a obtenção de êxito na busca de um melhor padrão de vida. Além disso, uma boa parcela dos entrevistados trabalha no mercado informal por meio dos chamados 'bicos'. No emprego informal, além de ser comum a remuneração abaixo do nível mínimo legal, os trabalhadores são privados dos benefícios de seguridade social, como aposentadoria entre outros. Não contando com uma renda fixa o que gera insegurança (IRIART, 2008).

Nesta localidade, verifica-se a inexistência ou precariedade do esgotamento sanitário e a disposição de resíduos sólidos a céu aberto, que acabam por induzirem a proliferação de insetos e roedores vetores e, consequentemente, doenças infecciosas relacionadas aos excretas, água empossada, lixo e vetores que atingem a população frequentemente, como relatado pelos entrevistados. Muitos percebem as problemáticas ambientais existentes no seu entorno, e entendem que são co-responsáveis por esta situação.

Os serviços que propiciam o acesso ao esgotamento sanitário e a coleta regular de lixo resultam em melhoria das condições de vida e em benefícios como controle e prevenção de doenças infecciosas, prática de hábitos higiênicos, conforto, bem-estar, aumento da expectativa de vida e da produtividade econômica (COSTA et al., 2005; FEWTRELL et al., 2005; VILLAR et al., 2008). Portanto, as diferentes formas de intervenção ambiental que tem como objetivo reduzir os efeitos sobre a pobreza, também acarretam benefícios para o meio ambiente. 'Agua mais limpa, ar mais puro e melhor saneamento não somente reduzirão a carga de doenças sobre os pobres como também produzirão um ambiente mais limpo de modo geral'.

Os moradores desta comunidade compreendem que não se deve jogar lixo nas ruas ou no rio. Alguns praticam a coleta seletiva o que demonstra certo nível de esclarecimento, mas olhando criticamente onde estão inseridos percebe-se que não existe uma tomada de atitude e um 
posicionamento crítico, preservacionista e participativo. O nível socioeconômico não se constitui em impedimento do ato de perceber o ambiente no qual se está inserido, mas a compreensão de que o ambiente natural e o modificado pelo homem deve ser protegido (WAKIL et al., 2004), pois isto é cuidar de si mesmo, ainda não foi alcançada.

Uma percepção ambiental positiva é caracterizada por ser uma tomada de consciência das problemáticas ligadas ao ambiente, sendo o processo pelo qual o indivíduo e a coletividade constroem valores sociais, conhecimentos, habilidades, atitudes e competências voltadas à conservação do meio ambiente, essencial à qualidade de vida e à sustentabilidade (VILLAR et al., 2008). Portanto, não se trata somente de um reconhecimento, mas de assumir uma postura crítica e de ação diante dos problemas expostos. Ao pouco recurso financeiro e os baixos níveis de escolaridade não pode ser atribuído como empecilho à participação do cidadão e nem a falta de esclarecimento, pois muitos conseguem distinguir o que se deve ou não fazer em relação às questões ambientais. Outro pesquisador fez as mesmas observações quando da realização de estudos em comunidades rurais do interior do Rio Grande do Sul e sugeriram a refutação da relação entre pobreza e degradação, seja direta ou inversa (WAKIL et al., 2004).

A constatação anterior está em desacordo com as ideias expostas no Relatório Brundtland, em 1987, que afirma que os países em desenvolvimento exercem um papel na degradação dos recursos naturais e ambientais até mesmo mais expressivo do que os países desenvolvidos, o que significa que a degradação ambiental está associada ao grau de pobreza da população. Outras pesquisas desenvolvidas nesse sentido reafirmam as proposições do Relatório raciocinando no sentido de que a degradação dos recursos naturais reduz a produtividade, resultando em empobrecimento (REARDON \& VOSTI, 1995; BARBIER, 2000). Este círculo sugere que a redução da pobreza irá, necessariamente, reduzir a degradação do meio ambiente, assim como a conservação e preservação do meio ambiente irá, necessariamente, reduzir a pobreza.

O avanço para uma percepção positiva (sociedade sustentável) é permeado de obstáculos, na medida em que existe uma restrita consciência na sociedade a respeito das implicações do modelo de desenvolvimento em curso (JACOBI, 2003). O autor atribui, ainda, às instituições sociais, aos sistemas de informação e comunicação e aos valores adotados pela sociedade uma parcela de culpa sobre o tipo de desenvolvimento predatório que vivenciamos e que impede uma mudança de comportamento por parte de cada cidadão. É necessário, portanto, uma participação mais efetiva de cada membro da sociedade no debate dos seus destinos, como uma forma de compreender os problemas, objetivos e encontrar soluções.

Fica evidente a importância de se conscientizar os cidadãos para que atuem de maneira responsável e mantenham o ambiente saudável no presente, para que no futuro saibam exigir e 
respeitar os direitos próprios e os de toda a sua comunidade, o que modificará suas relações com o ambiente tanto interiormente, como pessoa quanto como ser coletivo (REIS et al., 2012).

\section{CONCLUSÕES}

A situação ambiental é resultado direto e indireto das políticas públicas, econômicas e sociais, não podendo ser considerada independentemente dessas políticas que devem basear seu planejamento com base na realidade local, nas necessidades e interesses da população, nos recursos disponíveis e na legislação vigente. Deve-se, portanto, buscar promover o crescimento da percepção ambiental positiva, expandindo a possibilidade de a população participar do processo decisório, como uma forma de fortalecer sua corresponsabilidade na fiscalização e controle dos fatores que contribuem para a degradação ambiental. Contribuindo, dessa forma, de um modo mais participativo, concreto e questionador de todo o processo.

\section{REFERÊNCIAS}

BARBIER, E.. The economic linkages between rural poverty and land degradation: some evidence from Africa. Agriculture, Ecosystems and Environment, South Australia, v.82, p.355-370, 2000.

BATISTA, I. H.; ALBUQUERQUE, C. C.. Desenvolvimento sustentável: novos rumos para a humanidade. Revista Eletrônica Aboré, Manaus, v.3, p.1-14, 2007.

BUCK, S.; MARIN, A. A.. Educação para pensar questões socioambientais e qualidade de vida. Educar, Curitiba, v.25, p.197-212, 2005.

COSTA, S. S.; HELLER, L.; BRANDÃO, C. C. S.; COLOSIMO, E. A.. Indicadores epidemiológicos aplicáveis a estudos sobre a associação entre saneamento e saúde de base municipal. Engenharia Sanitária e Ambiental, Rio de Janeiro, v.10, n.2, p.118-127, 2005.

DIAS, G. F.. Atividades interdisciplinares de educação ambiental. São Paulo: Global, 1994.

DIAS, G. F.. Educação ambiental: princípios e práticas. São Paulo: Gaia, 1992.

FERNANDES, R. S.; VIEGAS, R.; GUANANDY, J. V.. Avaliação do perfil de cidadania ambiental de estudantes do ensino média técnico do CEFET - RJ. Revista eletrônica do Mestrado em Educação. Ambiental, Rio Grande, v.17, p.196-2013, 2006.

FEWTRELL, L.; KAUFMANN, R. B.; KAY, D.; ENANORIA, W.; HALLER, L.; COLFORD, J. M.. Water, sanitation and hyiene interventions to reduce diarrhea in less developed countries: a systematic review and meta- analysis. Lancet Infectious Disease, Maryland, v.5, p.42-52, 2005.

FORATTINI, O. P.. Qualidade de vida e meio urbano: a cidade de São Paulo. Revista Saúde Pública. São Paulo, v.25, n.2, p.75-86, 1991.

GUIMARÃES, M.; VASCONCELLOS, M. M. N.. Relações entre educação ambiental e educação em ciências na complementaridade dos espaços formais e não formais de educação. Educar em Revista, Curitiba, v.27, p.147-162, 2006.

IRIART, J. A. B.. Representações do trabalho informal e dos riscos à saúde entre trabalhadores domésticos e trabalhadores da construção civil. Revista Ciência e Saúde Coletiva, Rio de janeiro, v.13, n.1, p.165-174, 2008. 
JACOBI, P.. Educação ambiental, cidadania e sustentabilidade. Cadernos de Pesquisa, São Paulo, v.118, p.189-215, 2003.

PELICIONI, M. C. F.. Educação ambiental, qualidade de vida e sustentabilidade. Saúde e Sociedade, São Paulo, v.7, n.2, p.19-31, 1998.

PEDRINI, A.; COSTA, E. A.; GHILARDI, N.. Percepção ambiental de crianças e pré-adolescentes em vulnerabilidade social para projetos de educação ambiental. Ciência \& Educação, Bauru, v.16, n.1, p.163179, 2010.

RAZZOLINI, M. T. P.; GÜNTHER, W. M. R.. Impactos na saúde das deficiências de acesso a água. Saúde e Sociedade, São Paulo, v.17, n.1, p.21-32, 2008.

SCHWARZ, M. L.; SEVEGNANI, L.; ANDRÉ, P.. Representações da mata atlântica e de sua biodiversidade por meio dos desenhos infantis. Ciência \& Educação, Bauru, v.13, n.3, p.369-388, 2007.

REARDON, T.; VOSTI, S.. Links between rural poverty and the environment in developing countries: asset categories and investment poverty. World Development, Atlanta, v.23, n.9, p.1495-1506, 1995.

REIS, L. C. L.; SEMÊDO, L. T. A. S.; GOMES R. C.. Conscientização ambiental: da educação formal a não formal. Revista Fluminense de Extensão Universitária, Rio de Janeiro, v.2, n.1, p.47-60, 2012.

VILLAR, L. M.; ALMEIDA, A. J.; LIMA, M. C. A.; ALMEIDA, J. L. V.; SOUZA, L. F. B.; PAULA, V. S. A.. Percepção ambiental entre os habitantes da região noroeste do estado do Rio de Janeiro. Escola Anna Nery Revista de Enfermagem, Rio de Janeiro, v.12, n.3, p.537-43, 2008.

WAQUIL , P. D.; FINCO, M. V. A.; MATTOS, E. J.. Pobreza rural e degradação ambiental: uma refutação da hipótese do círculo vicioso. RER, Porto Alegre, v.42, n.2, p.317-340, 2004. 